\title{
ANTIEIGENVALUES AND ANTISINGULARVALUES OF A MATRIX AND APPLICATIONS TO PROBLEMS IN STATISTICS
}

\author{
C. RADHAKRISHNA RAO
}

\begin{abstract}
Different ways of characterizing antieigen and antisingularvalues are considered. Several matrix inequalities, their generalizations and applications to problems in multivariate statistics are given. A new concept of homologous canonical correlations is introduced and applied to a problem in genetics.
\end{abstract}

Mathematics subject classification (2000): 15A42, 62H20.

Key words and phrases: Kantorovich, Wielandt and Shisha-Mond inequalities, Khatri-Rao and Rao inequalities, Bloomfield, Watson and Knott inequalities, $G$-antieigenvalues and $G$-antieigenvectors, antisingularvalues, homologous canonical correlations.

\section{REFERENCES}

[1] G. AlPARGU, The Kantorovich inequality, with some extensions and with some statistical applications, thesis submitted to McGill University, Montreal, for the degree of Master of Science.

[2] T. ANDO, Majorization of eigenvalues, Lecture notes for lecture presented at the Special Conference on Functional Analysis and Linear Algebra, Indian Statistical Institute - Delhi Centre, January 3-7, (2000). preprint.

[3] T. ANDO, From determinant and trace inequalities to majorization of eigenvalues, Lecture notes for invited lecture to be presented at the Ninth International Workshop on matrices and Statistics, in Celebration of C. R. Rao's 80th Birthday (Hyderabad, India, December 9-13, 2000), preprint.

[4] T. ANDO, Bloomfield-Watson-Knott type inequalities for eigenvalues, Taiwanese J. Math., 5, (2001), 443-469. [Special Issue associated with ICMAA-2000.]

[5] F. C. BARTMANN, P. BloOMFIEld, Inefficiency and correlation, Biometrika, 68, (1981), 67-71.

[6] P. BLOOMfield, G. S. WATSON, The inefficiency of least squares, Biometrika, 62, (1975), 121-128.

[7] R. G. CAMERON, B. KouvaritaKIS, Minimizing the norm of output feedback controllers used in pole placement, Int. J. Control, 32, (1980), 759-770.

[8] R. G. CAMERON, Minimizing the product of two Rayleigh quotients, Linear and Multilinear Algebra, 13, (1983), 177-178.

[9] C. DAVIS, H. SChNeIDER, Helmut Wielandt: Mathematishe Werke/Mathematical Works - Volume 2, Linear Algebra and Analysis, Watter de Gruyter, Berlin, (1996), 156-162.

[10] S. W. Drury, S. Liu, C.-Y. Lu, S. Puntanen AND G. P. H. STyan, Some comments on several matrix inequalities with applications to canonical correlations: Historical background and recent developments, Sankhyā A. 64, (2002), 453-507.

[11] M. L. EATON, A maximization problem and its application to canonical correlation, J. Multivariate Anal., 6, (1976), 422-425.

[12] R. FRUCHT, Sobre algunas desiguldades: Observacion relativa a la solución del Problema $N^{\mathrm{O}}$ 21, indicada por el Ing. Ernesto M. Saleme (1942) (with an untitled appendix by Beppo Levi), MathemasticæNotæ-Boletin del Instituto de Mathemática (Rosario), 3, (1943), 41-46.

[13] W. GReub, W. RheInBoldt, On a generalization of an inequality of L. V. Kantorovich, Proc. Amer. Math. Soc., 10, (1959), 407-415.

[14] K. E. GUSTAFSON, The angle of an operator and positive operator products, Bull. Amer. Math. Soc., 74, (1968), 488-492. 
[15] K. E. Gustafson, The geometrical meaning of Kantorovich-Wielandt inequalities, Linear Algebra and Appl., 296, (1999), 143-151.

[16] K. E. GUSTAFSON, An extended operator trigonometry, Linear Algebra Appl., 319, (2000), 117-135.

[17] K. GuSTAFSON, Quantum trigonometry, infinite dimensional analysis, Quantum Probability and Related Topics, 3, (2000), 33-52.

[18] K. GuSTAFSON, Operator trigonometry of statistics and economics, Linear Algebra Appl., 354, (2002), $141-158$.

[19] K. E. Gustafson, D. K. M. RaO, Numerical Range: The Field of Values of Linear Operators and Matrices, Springer, Berlin, (1997).

[20] L. KANTOROVICH, Functional Analysis and Applied Mathematics (translated from the Russian Edition (1948)), Report No.1509, Washington, D.C.: National Bureau of Standards, (1952).

[21] T. KATO, Perturbation Theory, (Second Edition, Chapter 2), Springer Verlag, (1980).

[22] C. G. KHATRI, Some optimization problems with applications to canonical correlations and sphericity tests, J. Multivariate Analysis, 8, (1978), 453-467. Correction (1982), J. Multivariate Analysis, 12, 612.

[23] C. G. KHATRI, C. R. RAO, Some extensions of Kantorovich inequality and statistical applications, J. Multivariate Analysis, 11, (1981), 499-505.

[24] C. G. KhATRI, C. R. RAO, Some generalizations of Kantorovich inequality, Sankhyā A, 44, (1982), 91-102.

[25] R. KHATTREE, On the calculation of antieigenvalues and antieigenvectors, J. Interdisciplinary Mathematics, 4, (2001), 195-199.

[26] R. KHATTREE, On generalized antieigenvalue and antieigenmatrix of order $r$, American J. Math. Management Sci., 22, (2002), 89-98.

[27] R. KhatTREe, Antieigenvalues and antieigenvectors in statistics, J. Stat. Planning and Inference, 114, (2003), 131-144.

[28] M. KNOTT, On the minimum efficiency of least squares, Biometrika, 62, (1975), 129-132.

[29] B. Kouvaritakis, R. G. CAMERON, Pole placement with minimized norm controllers, Proc. IEEE, 127, (1980), 32-36.

[30] M. G. KREIN, Angular localization of spectrum of a multiplication integral in Hilbert space, Func. Anal. and Applic., 3, (1969), 89-90.

[31] C. R. RAO, Least squares theory using an estimated dispersion matrix and its application to measurement of signals, In Proc. Fifth Berkeley Symposium on Mathematical Statistics and Probability, Vol.1, University of California Press, (1967), 355-372.

[32] C. R. RaO, Linear Statistical Inference and its Applications (Second Edition), John Wiley, New York, (1973).

[33] C. R. RAO, The inefficiency of least squares, Linear Algebra and Appl., 70, (1985), 249-255.

[34] C. R. RAO, C. VEERENDRA RAO, Stationary values of two Rayleigh quotients: Homologous canonical correlations, Sankhyā, 49, (B) (1987), 113-125.

[35] C. R. RAO, M. B. RAO, Matrix Algebra and its Applications to Statistics and Econometrics, World Scientific, Singapore.

[36] O. SHISHA, B. MOND, Bounds on difference of means, In Inequalities: Proceedings of a Symposium held at Wright-Patterson Air Force Base, Ohio, August 19-27, 1965, Academic Press, New York, (1967), 293-308.

[37] W. G. StRang, On Kantorovich inequality, Proc. Amer. Math. Soc., 11, (1960), 468.

[38] G. P. H. STYAN, On some inequalities associated with ordinary least squares and the Kantorovich inequality, In Festschrift for Eino Haikala on his Seventieth birthday, Univ. of Tampere, (1983), 158-166.

[39] W. VENABLES, Some implications of the union intersection principle for tests of sphericity, J. Multivariate Anal., 6, (1976), 185-190.

[40] H. WiELANDT, Inclusion theorems for eigenvalues, In Simultaneous Linear Equations and the Determination of Eigenvalues (Eds. L.J. Paige and O. Taussky), National Bureau of Standards Applied Mathematics Series, Vol 29, (1953), 75-78. 